WwW.itcon.org - Journal of Information Technology in Construction - ISSN 1874-4753

\title{
VR - ROADMAP: A VISION FOR 2030 IN THE BUILT ENVIRONMENT
}

PUBLISHED: August 2009 at http://www.itcon.org/2009/32

EDITORS: Kazi A S, Aouad G, Baldwin A

\author{
Nashwan Dawood, Professor \\ Centre for Construction Innovation and Research (CCIR), University of Teesside, Middlesbrough, TS1 $3 B$ A, \\ n.n.dawood@tees.ac.uk
}

SUMMARY: VR is an emerging technology that will greatly benefit the construction industry and its supply chain in terms of capacity to experiment, greatly improved communication, data visualisation and capturing ideas. This paper presents the outcome of a research project that was aimed at developing a 'VR roadmap: vision for 2030 in built environment'. The methodology used was to thoroughly review previous and current application of VR in the construction and manufacturing based industries and conduct brain storming sessions with Experts in IT/VR regarding future functionalities and $R \& D$ needed to develop VR tools and processes capable of supporting future built environment. Twenty three Experts from industry and academia from UK, EU and USA working in diverse roles in academia, industry and software development were invited to participate in a brain storming sessions over two-day workshops. The roadmap is focussed on three main themes: current state-of-the-art of VR in built environment; technology and process specifications towards 2030 and R\&D plans to deliver such specifications. Discussions were focussed on identifying enablers, barriers, opportunities and challenges that prevail in the industry and those likely to be encountered towards 2030 with advancement of the technology and process changes. The paper introduces and discusses the roadmap and its related methodology.

KEYWORDS: VR application, Design, Construction, Roadmap

REFERENCE: Dawood N (2009) VR-roadmap: a vision for 2030 in the built environment, Journal of Information Technology in Construction (ITcon), Vol. 14, Special Issue Next Generation Construction IT: Technology Foresight, Future Studies, Roadmapping, and Scenario Planning, pg. 489-506, http://www.itcon.org/2009/32

COPYRIGHT: (C) 2009 The authors. This is an open access article distributed under the terms of the Creative Commons Attribution 3.0 unported (http://creativecommons.org/licenses/by/3.0/), which permits unrestricted use, distribution, and reproduction in any medium, provided the original work is properly cited.

\section{INTRODUCTION}

For any industry to survive and be a world class player, it needs to innovate. Construction is no exception. The construction industry needs to innovate by searching and experimenting for and with better products and processes that ensure its survival. This need has been highlighted and emphasised by the Egan report and other government and industry sponsored initiatives.

The developments in VR and its use within construction have proved to be of great benefit to users who have embraced the technology. VR technologies can be applied to promote innovation by allowing the construction industry to better explore possible future products and services. This has been the subject of discussion and debate for over 8 years. During this period a number of projects and reports have been commissioned by the EPSRC and the DTI (UK Business potential for Virtual Reality, 2000). Further developments in the field and innovative means of utilisation are likely to continue.

One of the major conclusions of these studies was that VR is an emerging technology that will greatly benefit the construction industry and its supply chain in terms of capacity to experiment, greatly improved communication, data visualisation and capturing ideas. The last Foresight Report recommended greater VR use in construction. From an industrial point of view, the introduction of VR will add value in the form of: 
- Greater site safety - by ability to view pinch-points of projects in terms of restricted access (spatial planning).

- Ability to test alternative construction methods and note the time implication on each.

- Allow more accurate sequencing of operations via the ability to view element interfaces.

- $\quad$ Present a new channel of communication between designers/suppliers/and contractors.

Watts et al (1998) stated that VR can help the innovative organisation in the following respect:

- Low marginal cost --> Capacity to experiment

- $\quad$ Realism/accessibility --> Involving all

- Interactivity --> Capturing ideas

It is clear from the above that VR can play a mjor part in achieving innovation in the indsutry. There are ample VR tools that are developed from resaerch or/and commercial activities around the world that support this concept. It is intended to learn from other industrial experiences - the results of the application of VR to various sectors of engineering have so far been tremendous (Boyd 1998; Wilson 1996). VM has been shown to avoid costly mistakes, and enable planners and managers to envision the whole manufacturing process from design and assembly to product shipping. Factory simulation has helped to make substantial savings on tooling, design, construction and installation. Compared to the use of conventional methods, VM has also been shown to dramatically reduce the amount of time it takes to analyse new design concepts and incorporate them into the production process. It has enabled decision-makers to make last minute changes and eliminated the need to build prototypes (Quayle, et al 2005). The application of VR has made it much easier for factory workers to accomplish complex and error-prone tasks, and has also offered a safer environment for testing various manufacturing techniques.

Increasing globalisation is driving the construction industry towards increased competitiveness and in improving efficiency. The current key business drivers were seen to be the need for; efficiency improvements, cost reduction, increased collaboration, ease of communications, involvement of the client and end users in the whole construction process, accurate progress measurement and modelling of the as-built environment. There are significant benefits that VR could offer to the industry, the construction industry is not adopting VR to its full capacity when compared to the aerospace, automotive and other manufacturing industries. Current applications of VR are used mainly for client walkthroughs, design reviews and the visualisation of construction sequences. The technology is being pushed by the academia or developers and the fragmented and adversarial culture in the industry has to be changed in order to develop the industry and make it more technology based and agile. However, there is a need of simple and easy use cases of applications in the built environment.

To date there is no future vision for R\&D development that is focused on VR application to construction products and processes. In this context the objective of the paper is present the output of research project with the aim of developing a visionary VR roadmap for 2030 to support future Built Environment. It is hypothesised that future built environment will be more intelligent (self diagnostic, real time communication for facilities management etc.), flexible, secure, sustainable and with high value to stake-holders

The reminder of the paper discuss the methodology used and deliverables of the 'VR Roadmap: vision for 2030' initiative.

\section{DEVELOPMENT METHODOLOGY OF THE ROADMAP}

A though literature review of both academic and industry was conducted to identify state-of-the-art of VR R\&D. This included current roadmap initiatives like FIATECH, RoadCON and $\mathrm{nD}$ initiative.

The following shows briefly the current state-of-the-art of R\&D against construction business processes:

- Initiation and outline design: $\mathrm{R} \& \mathrm{D}$ is mainly in the area of walkthrough of $3 \mathrm{D}$ visualisation models, augmented reality application and communication systems of outline design information, urban visual planning (Miles et al 2004) 
- $\quad$ Design development: R\&D in the area of visual design, 3D/nD modelling and sketching, product models and integrate with VR and search based engines for finding optimal design solutions (Tizani et al 2005, Khatab et al 2005, Wu, A, el al 2004 )

- $\quad$ Contract and pre-construction: mostly VR used in marketing and information visualisation like cost, quantities, 4D models, etc (Dawood et al, 2005, Dawood et al 2006, Rischmoller L, et al, 2001)

- Construction: R\&D is focused on visual construction, 4D modelling, construction sequencing, image analysis, simulation modelling etc.

- Maintenance: Very little work in the area and most of the work is focused on assets information visualisation and simple augmented reality application.

Table 1 gives a list of the state-of-the-art of developments of visualisation and integrated technologies in the built environment with respect to their intended functions.

TABLE 1: Current Applications of VR in Built Environment

\begin{tabular}{|c|c|}
\hline Functions & Details \\
\hline $\begin{array}{l}\text { Collaboration/ } \\
\text { interdisciplinary work }\end{array}$ & $\begin{array}{l}\text { - Compilation of VR models to build prototypes to represent } \\
\text { interdisciplinary work. } \\
\text { - Developing user interfaces for designers }\end{array}$ \\
\hline Standards & $\begin{array}{l}\text { - } \text { IFC development for CAD } \\
\text { - } \text { CAD and VR data exchange } \\
\text { - Linking with GIS IAI, IFC mapping }\end{array}$ \\
\hline Whole life costing analysis & $\begin{array}{l}\text { - Visual Costing } \\
\text { - What-if analysis } \\
\text { - Operation analysis }\end{array}$ \\
\hline Modelling and design & $\begin{array}{l}\text { - Digital Architecture - design spatial analysis. } \\
\text { - Early stage of design - integration of VR model, with structural } \\
\text { model, collusion checking }\end{array}$ \\
\hline Planning & $\begin{array}{l}\text { - 4D modelling process information linked to VR objects } \\
\text { - Urban planning/GIS/VR integration }\end{array}$ \\
\hline $\begin{array}{l}\text { Progress measurement and } \\
\text { modelling As-built } \\
\text { Information }\end{array}$ & $\begin{array}{l}\text { - Image Capture } \\
\text { - Laser scanning technology for the built environment, integration } \\
\text { with presentation technologies, object recognition. }\end{array}$ \\
\hline Communication & $\begin{array}{l}\text { - Visualisation/Walkthrough } \\
\text { - } 3 \mathrm{D} / 4 \mathrm{D} / \mathrm{nD} \text { visualisations } \\
\text { - Mobile and grid technology to communicate visual data. }\end{array}$ \\
\hline
\end{tabular}

As can be seen from table 1 , there is very promising R\&D projects and limited commercial systems for visualisation and integration of building information models. The current construction industry structure is characterised as fragmented, encompassing adversarial relationships and sequential in delivering products and services. However, the industrial processes are changing due to changes in procurement methods such as PFI projects requiring increased efficiency, flexibility and use of IT technology. Client requirements and the culture of working from traditional approaches to partnering, concurrent engineering has led the industry to adopt new communications technologies. The industry should continuously adapt new technologies including VR technologies to improve efficiency of delivering construction projects. The lack of education, training and skills to drive the VR technology in the industry as well as lack of proven case studies have been major factors for the low uptake of technology in the practice.

The cost of technology is high especially if it is based on single project (unless projects are very high in value like T5, the Willis building, etc). Research initiatives such as Industry Foundation Classes (IFC) are attempting to develop common standard for data interoperability in the applications and the development of XML and internet technology, increasing computer power in both data handling and processing power have been the drivers for the development and application of VR in Built Environment.

Standardisation of the data interoperability and communication of different VR applications with cost, method statement and other information models is very crucial to encourage the use of VR technologies in the built 
environment. Big clients can enforce the use of technology and such clients must be targeted and awareness must be created through case studies so that the industry could recognise how the technology will support the delivery of projects and can recognise how the risk of using technology will be driven out. Education and training of VR to the industry practitioners should be given a priority.

This review was followed by brain storming sessions over two-day workshops and presentations by VR experts. The objective was to establish and develop 'VR Roadmap: vision for 2030'. In order to achieve this, twenty three experts were attended and participated in a two-day workshops at Manchester Thistle airport in the UK. The participants of the workshop had diverse experience in the use of VR technology. The experience of the participants include development of hardware and software technologies, VR modelling, socio-economic analysis on the use of VR, teaching and training, application of VR in industrial projects.

The workshop included presentations from experts which highlighted current practices and three main workshops were used to brainstorm and develop the vision for 2030 of the application of VR and a vision for research and development for the coming 2030. Discussions were focussed on identifying enablers, barriers, opportunities and challenges that prevail in the industry and those likely to be encountered towards 2030 with advancement of the technology and process changes. The following section discuss the pre-workshop data collection and analysis of such data.

\section{PRE-WORKSHOP DATA COLLECTION AND ANALYSIS}

Experts were asked to complete a semi-structured questionnaire prior to the workshop event. The objective was to elicit their knowledge and expectations of future VR roadmap. This was important to ascertain a successful outcome of the workshop.

The following lists a summary points of the participants expectations of the workshop (this need to be tie in with the major deliverables of the net-wok)

- $\quad$ Identify novel ideas, processes, trends and developments of VR.

- $\quad$ Networking, know what others are doing and identify opportunities for research collaborations

- Clear strategy to promote real benefits of VR as cost effective real application, not just an expensive toy

- Appreciation of current research projects and opportunities for liaison with international practice

- $\quad$ Obtain feedback and vision to improve VR software

- $\quad$ Raise the topic of VR standards

- $\quad$ Future vision and an agreed policy on the requirements and functionality of VR.

- VR applications in workflow of construction and Civil Engineering projects.

The main key functionalities that were identified by experts prior to the workshop are:

- $\quad$ Key tool for project delivery

- Aid collaborative design, concurrent engineering, digital architecture and fabrication

- $\quad$ Simple for use in communicating design and construction process-new generation tool

- $\quad$ Object classification.

- Focus on how to deliver simple, cost effective solutions and easily accessible to Architect/ Designer/contractors/sub-contractors

- $\quad$ Increase in stereoscopic and immersive 3D usage; 3D displays (distinct from pseudo 3D displays)

- A paradigm shift of how we do things from CAD to much more 3D visualisation

- $\quad$ Stronger link to the industry and research and development to deliver what industry requires 
The experts were of the view that VR is just being used as a visualisation tool and $2 \mathrm{D}$ application of CAD is prevailing in the industry. There is a need for industry and academia to work very closely and deploy the technology to its full capacity. The cultural, technical and other socio-economic barriers must be tackled for to bring efficiency and enhance the performance of the industry and development focus should consider education, training of the industry and stake holders as well as development of natural interfaces. A paradigm shift is necessary.

The next section discusses the operations of the workshop and main outputs.

\section{OPERATION OF THE WORKSH: SETTING THE SCENE}

To inform the formation of a new VR roadmap, the research team at Teesside reviewed various reports such as Construction 2020, FIATECH, nD workshops, EU IT Roadmap and Intelligent infrastructure documents. Issues regarding the Role of VR as Enabling Technology Towards 2030, barriers, challenges and requirements were identified and presented to the participants. The aim was to introduce and familiarise the participants with current IT roadmaps initiatives and direct them towards achievement of the aims and objectives of the workshops. This is followed by three brain storming sessions to tackle the development of the vision and the development of the roadmap. Experienced facilitators for each session was appointed and all sessions were video taped for further analysis. The following sections discuss the sessions of the workshops.

\section{BRAIN STORMING SESSION 1: DEVELOPMENT OF THE VR VISION FOR 2030}

The objective of this session is to collaboratively develop a VR vision for 2030 which will form the foundation for the proposed roadmap. This session was divided into two groups. First group looked into the development of technical specification for the Roadmap and identified challenges and opportunities (see Table 2). The second group discussed the development of process specification for the Roadmap and identifying challenges and opportunities (see Table 3).

TABLE 2: Process Specifications

\begin{tabular}{|c|c|c|}
\hline Process Specifications & Challenges & Opportunities \\
\hline $\begin{array}{l}\text { - } \text { Globalisation / } \\
\text { - Encalisation } \\
\text { - Sustainability } \\
\text { - De-fragmentation- } \\
\text { Integration } \\
\text { - Computerisation - } \\
\text { Optimisation of } \\
\text { technology } \\
\text { - Common Standard } \\
\text { - Diversity/ Flexibility } \\
\text { - Automated (Semi) } \\
\text { building manufacture } \\
\text { - Specialisation/ } \\
\text { Complexity } \\
\text { - Whole life cycle model } \\
\text { of building } \\
\text { Information } \\
\text { management } \\
\text { (representation and use) } \\
\text { to match technology } \\
\text { and process changes } \\
\text { - Product model should } \\
\text { support process model }\end{array}$ & $\begin{array}{l}\text { - Data interoperability } \\
\text { - Cultural issues } \\
\text { - Scale of construction projects } \\
\text { (height etc) } \\
\text { - Sustainability } \\
\text { - Smart materials } \\
\text { - Design structure integrity } \\
\text { - User perception/ clients } \\
\text { - Hequirement capture } \\
\text { - Sealth and safety } \\
\text { - Shifting professional roles and } \\
\text { - Responsibilities } \\
\text { - Maintain energy efficiency } \\
\text { - Include maintenance of } \\
\text { - Eacilities } \\
\text { - Education of construction } \\
\text { workforce }\end{array}$ & $\begin{array}{l}\text { - Mass customisation } \\
\text { - Reality/VR integration } \\
\text { - Efficiency drivers- Time, } \\
\text { - Cost Performance } \\
\text { - Increased safety } \\
\text { - Increased buildability } \\
\text { - Alternative materials } \\
\text { - Professional integration } \\
\text { - Shortened life cycle }\end{array}$ \\
\hline
\end{tabular}


TABLE 3: Technology Specifications

\begin{tabular}{|c|c|c|}
\hline Technology Specifications & Opportunities & Challenges \\
\hline $\begin{array}{l}\text { Tools to be used in } \\
\text { whole life cycle of the } \\
\text { projects } \\
\text { - Full control/interactive } \\
\text { - Object Modelling a } \\
\text { "new way of thinking" } \\
\text { - Communicate 3D/ } \\
\text { objects to project team } \\
\text { - Use 3D from the } \\
\text { beginning } \\
\text { - Link and provide design } \\
\text { process functions such } \\
\text { as sustainability, energy, } \\
\text { maintenance etc. }\end{array}$ & $\begin{array}{l}\text { - Cost dropping } \\
\text { - Generic objects/ } \\
\text { components/library- office } \\
\text { metaphor } \\
\text { - Parametric } \\
\text { modelling/Object modelling } \\
\text { - Feed data in different ways. } \\
\text { - Realism v artistic (game) } \\
\text { depends upon task/views } \\
\text { - Embedded intelligence } \\
\text { - 3D plane } \\
\text { - Free channel of } \\
\text { communication (motion, } \\
\text { sound etc) } \\
\text { - User interface "Selling the } \\
\text { dream" } \\
\text { - Structure data } \\
\text { - Language/ technology } \\
\text { Visual scale }\end{array}$ & $\begin{array}{ll} & \text { Change } \\
\circ & \text { Legislation } \\
\circ & \text { Globalisation } \\
\circ & \text { Competition } \\
\circ & \text { Generation shift } \\
\circ & \text { Energy/sustainability, } \\
\text { production + efficiency } \\
\circ \text { Generic/ proprietary } \\
\text { standards, interoperability } \\
\circ \text { Archive data (file not } \\
\text { found) } \\
\circ \text { Education/ new knowledge } \\
\text { social gap } \\
\circ \text { Drive technology not just } \\
\text { use it } \\
\circ \quad \text { Dynamics of software } \\
\text { industry } \\
\text { Skills, training/education }\end{array}$ \\
\hline
\end{tabular}

In conclusion, VR will play a major role in the design, management and operation of the Built Environment embracing the "Cradle to Grave" concept. VR will be linked to other applications with a natural interface. Following the advancement in the mobile technology, construction processes will be more intelligent and will utilise VR technology. The drivers or changes in Technology and Research towards 2030 will be:

- $\quad$ Customer understanding: Client lead required to force change

- Public Participation:

- $\quad$ End user involvement, urban and building development in planning process

- Government regulations, legislation

- $\quad$ Sustainability

- $\quad$ VR software to simulate and access and analyse

- Incentive- low cost technology

- Competition to provide efficient and quality products/services

- $\quad$ Requirements for knowledge economy

- Internet and mobile technologies: E-submission, VR planning

- Increased partnering, and collaboration.

- $\quad$ Energy conscious stake holders (designers, builders, occupiers, owners)

\section{BRAIN STORMING SESSIONS 2 \& 3: THE VR ROADMAP: VISION FOR 2030}

Figure 1 shows an outline of the roadmap which was developed during session 2 and 3 of the workshops. There are three components to the roadmap: construction processes, function and specification of VR and R\&D initiatives. It is envisaged that the deliverables of the roadmap in 2030 will be the creation and use of highly intelligent electronic product and processes descriptions within virtual environment for performing all business analysis of built environment that consider all aspects of the whole life cycle. This will allow built environment stake-holders (owners, designers, users, supply chain, etc) to develop, design, test, rehearse, procure, built and maintain their facilities in a concurrent and integrated fashion with high certainty of value, usability and very low environmental impact. 


\begin{tabular}{|c|c|c|c|c|c|}
\hline & $\begin{array}{l}\frac{\text { Initiation }}{\text { Scenario based project }} \\
\text { planning requirement } \\
\text { capture }\end{array}$ & $\frac{\text { Design Development }}{\text { Automated Design }}$ & $\begin{array}{l}\text { Contract } \\
\text { Integrated } \\
\text { procurement }\end{array}$ & $\begin{array}{l}\frac{\text { Construction }}{\text { Intelligent and }} \\
\text { automatic construction } \\
\text { jobsite }\end{array}$ & $\begin{array}{l}\text { Maintenance } \\
\text { Intelligent self } \\
\text { maintaining } \\
\text { operational facilities }\end{array}$ \\
\hline Current State of the Art & $\begin{array}{l}\text { Walkthrough } \\
\text { 3D CAD } \\
\text { Augmented Reallyy }\end{array}$ & 3D CAD/Product Modelling & $\begin{array}{l}\text { Method Slatements Tender } \\
\text { Documents } \\
\text { Marketing }\end{array}$ & $\begin{array}{l}\text { Walkhroughs, PDAs } \\
\text { Visualisation of construction } \\
\text { sequences } \\
\text { Image capture }\end{array}$ & $\begin{array}{l}\text { Asset management tools } \\
\text { Augmented/mixed reality } \\
\text { applications }\end{array}$ \\
\hline $\begin{array}{c}\text { Future VR Technology } \\
\text { Specifications }\end{array}$ & $\begin{array}{l}\text { End users as designers } \\
\text { Generic object blocks } \\
\text { VR as a laboratory }\end{array}$ & $\begin{array}{l}\text { 3D Object Modelling } \\
\text { Parametic modelling } \\
\text { Energy efficiency } \\
\text { Sustainable design tool } \\
\text { VR linked to structural design } \\
\text { VR models of interior and utilities }\end{array}$ & $\begin{array}{l}\text { E-Automated Portals (Or-line } \\
\text { viewing of models, construction } \\
\text { sequences) }\end{array}$ & $\begin{array}{l}\text { Amblent Access } \\
\text { Embedded Intelligence and } \\
\text { interaction }\end{array}$ & $\begin{array}{l}\text { Self Diagnostic systems } \\
\text { Smart materials }\end{array}$ \\
\hline Business Drivers & $\begin{array}{l}\text { Realistic Client requirements } \\
\text { Professional Integration } \\
\text { Globalisation }\end{array}$ & $\begin{array}{l}\text { Wireless technologies } \\
\text { Flexble working patterns } \\
\text { Multidiscipilinary-collaborating } \\
\text { leams } \\
\text { Powerul computing power } \\
\text { Ageing population }\end{array}$ & $\begin{array}{c}\text { Internet technologies } \\
\text { Mobile:Wireless/GPSIGrid } \\
\text { technology } \\
\text { Globalisationlocalisation }\end{array}$ & $\begin{array}{l}\text { Sustainability } \\
\text { Consituction Population } \\
\text { educated in ICT } \\
\text { Complex projects } \\
\text { Scale of construction } \\
\text { Integration of Product and } \\
\text { processes } \\
100 \% \text { certianty in time, cost. } \\
\text { performance and quality }\end{array}$ & $\begin{array}{l}\text { Sustainability } \\
\text { Technology } \\
\text { Smart Materials } \\
\text { Computer Power } \\
\text { Educated Users }\end{array}$ \\
\hline Challenges & $\begin{array}{c}\text { Retaining Creativity } \\
\text { Low cost Technology } \\
\text { Personal Preferences } \\
\text { User triendliness of the technology }\end{array}$ & $\begin{array}{l}\text { Sustainability } \\
\text { Social Context } \\
\text { Intellectual Property Rights } \\
\text { Security of Intormation } \\
\text { Design friendly technology } \\
\text { Common standards }\end{array}$ & $\begin{array}{l}\text { Security } \\
\text { IPR } \\
\text { Educated and trained users } \\
\text { Cost of the technology }\end{array}$ & $\begin{array}{l}\text { Data protection, Security, } \\
\text { Human and Natural Resources } \\
\text { Educated and trained users } \\
\text { Low cost and affordable } \\
\text { technology }\end{array}$ & $\begin{array}{l}\text { Aging population } \\
\text { Renewal energy } \\
\text { Sustainability } \\
\text { Social Inclusion }\end{array}$ \\
\hline $\begin{array}{c}\text { Research\& } \\
\text { Development } \\
\text { initiatives for the next } \\
25 \text { years }\end{array}$ & $\begin{array}{l}\text { Natural Interfaces } \\
\text { Hapicic Interfaces } \\
\text { Business case } \\
\text { Thematic and Topological } \\
\text { visualisation } \\
\text { Knowiedge Management } \\
\text { Spatial reasoning }\end{array}$ & $\begin{array}{l}\text { Happic Interactions, Augmented } \\
\text { and Mixed reallies } \\
\text { Standardisation } \\
\text { Intelligent Objects/ } 30 \text { object } \\
\text { modelling } \\
\text { Spatial reasoning, resource } \\
\text { optimisation } \\
\text { Knowledge Management }\end{array}$ & $\begin{array}{c}\text { Ambient Access } \\
\text { Collaborating (virtual) teams/ } \\
\text { Technology } \\
\text { Value Enginering (i.e. Smart } \\
\text { materials) }\end{array}$ & $\begin{array}{c}\text { Ambient Access } \\
\text { Standardisation } \\
\text { Natural Interfaces } \\
\text { Construction process } \\
\text { simulation }\end{array}$ & $\begin{array}{l}\text { Socio-economic use of VR } \\
\text { Whole life cycle modelling } \\
\text { Real-ime integration and } \\
\text { presentation } \\
\text { Intelligent data models } \\
\text { Simulation }\end{array}$ \\
\hline
\end{tabular}

\section{FIG. 1: VR Vision 2030: research, development and application of VR in the Built Environment}

The Roadmap is highly influenced and focused on future built environment, business drivers and challenges. In delivering a 'VR Roadmap: A vision for 2030', the experts have asked defined what futuristic built environment they foresee and they agreed on the following specification:

"Sustainable Energy - renewable, Intelligent Controls, Smart Materials, Common Standards, Advanced Security, Self Diagnostic \& Healing Buildings/Facilities, Intelligent Interfaces With Buildings/Facilities, $100 \%$ Certainty In Time, very high Cost Performance \& Quality \& H\&S, Space Efficiency and Flexibility"

This was important in order to focus the mind on the tools, methods and functions that are needed to deliver the futuristic built environment. In parallel to this, the experts developed futuristic business drivers and challenges. 
Figure 1 shows a matrix futuristic construction business processes (Scenario based project planning requirements capture, automated design, integrated procurement, intelligent and automatic construction jobsite and maintenance) against currents state of the art, future VR spec, business drivers, challenges and R\&D for the next 25 years. The figure provides a very abstract of the conclusion of the roadmap sessions.

VR prototyping was seen as being much simpler and efficient when it is assisted by the advent of standard object models of building components and structural members. As ambience is improved and global standards are developed, natural interfaces and immersive 3D usage will be able to better capture stack-holders and user requirements.

Design and VR modelling toward 2030 was seen as being much simpler assisted by the advent of standard object models of building components and structural members. As ambience is improved and global standards are developed, natural interfaces and immersive 3D usage will be able to capture client and user requirements and there will be a high diffusion of the use of augmented reality. The paradigm shift from the use of 2D CAD today to $3 \mathrm{D}$ visualisation will make it possible to provide visual simulation of the whole construction process enabling the simulation and testing of several scenarios in a VR environment before investment decisions are made. Moves towards full collaboration and potentially a polarisation of the industry will take place. The integration of the supply chain into the whole construction process will take place partially as a result of the adoption of modular construction methodology but also as a result of increased standardisation. Seamless supply chain streams to expert construction operations will speed up the construction process and improved efficiency/productivity will evolve from the capability to rehearse and simulate construction activities. Moves towards the integration of VR into university teaching courses were seen as being important in the further development of the knowledge and use of the technology in industry.

More intelligence will be incorporated into buildings with improved control applied to their maintenance. The interior fitting out process will be modelled with full involvements and modelling of end user/client requirements. Buildings will be constructed in a sustainable manner with smart materials and recognition given to the de-construction process and the carbon footprint of the materials and components used during construction.

The view of the experts was that there would be movement towards the increased use of stereoscopic and immersive 3D usage as opposed to pseudo 3D displays. R\&D activity into the extended use of VR and simulation in the town and road planning aspects of the built environment was seen as being capable contributing major improvement in these areas. Finally, industry and academia will need to work more closely to develop simple methods to use VR tools that construction industry requires.

Academia has not proven the case, little measurement of the undoubted benefits from the use of VR platforms has been undertaken. With the availability of proven value benefits, industry will justify the need for taking more time planning and measuring the progress using VR, by improved efficiency and collaboration, inherent from the use of VR during the execution and the after build life cycle phases of a construction project. There are opportunities from the use of ambient interfaces, improved standardisation, image capture, end user involvement in design, laser scanning, object recognition and other emerging technologies that can be seamlessly integrated with VR technology. Breaking down the traditional construction approach was seen as greatest barrier to further development of the technology with major opportunities to increase collaboration, improve communication and efficiency from the adoption of the technology.

The industrial uptake of technology is currently low and to accelerate its utilisation in the Built environment, it is essential to set up priority by the government, overcome cultural barriers and train the workforce to use the technology. Once the industrial application catches up with other industries with reinforcement from research and development of application to match the requirement of construction industry, VR will be a common place for the construction industry towards 2030. The collaboration will include the virtual teams, integration of multiple machines and resources independent of geographical locations.

There was significant debate as to whether or not VR modelling was being pushed by academia or pulled by industry. The consensus was that it was still being pushed by academia though there are some positive signs of change. VR technology is currently used mainly for client walkthroughs, there is an essential need to change the industry culture from a fragmented structure, with adversarial relationships still existing in some areas. The current key business drivers were seen to be the need for; efficiency improvements, cost reduction, increased collaboration, ease of communication, involvement of the client and end users in the whole construction process, accurate progress measurement and modelling of the as-built environment. 


\section{R AND D ACTIVITIES FOR NEXT 25 YEARS}

The research and developed activities identified to achieve the VR Vision 2030 is focussed on the development of VR hardware and software systems, development of common standards to ensure data interoperability, developing skills required for changing business requirement and developing VR to include whole life cycle analysis of Built Environment. The research and development activities will bridge the gap between the current state and vision state in 2030 and contribute to forward thinking process. Figure 2 shows a summary of the R\&D needed to deliver the vision toward 2030. It shows the R\&D needed against each business processes and functions needed. The following summarises the proposed R\&D (figure 4 gives an elaborate summary of the roadmap)

\footnotetext{
- $\quad$ Product and Process Visualisation

- Development of standard/flexible VR object models that are easy to access/use, web enabled

- $\quad$ Explore XVL, X3D and other web enabled VR

- Development of intelligent/visual search/agent based tools to enable the outline and detailed design process

- $\quad$ Predictive and interactive tools for design and construction planning

- Gesture and tangible interfaces to communicate with the VR models to retain creativity and accurate requirements capture from users and stakeholders.

- Development of tools for whole life cycle analysis (WLC) of built environment and infrastructure (cost, H\&S, time, environmental impact, materials modelling, security)

- Development of innovative product data manager

- Development of wireless and grid enabled technology

- Development of visual site construction process simulation (space analysis, logistics, 4D, nD, resources interaction, GPS control)

- Real-time and visual control of facilities operations through smart materials

- $\quad$ Cost/Value analysis of visual/intelligent tools and methods

- AR application throughout the construction processDevelopment of education and training materials

- Development of accurate Image and video analysis for process control (progress/materials control, schedule monitor, etc)
} 


\begin{tabular}{|c|c|c|c|c|c|c|c|c|c|c|c|c|c|}
\hline 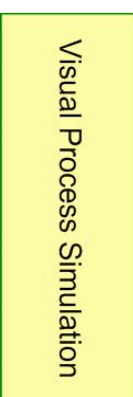 & 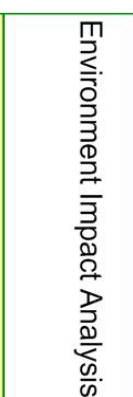 & 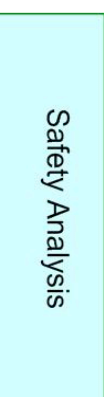 & 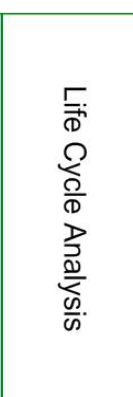 & 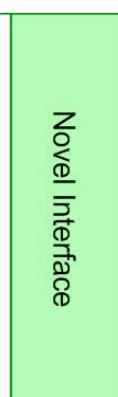 & 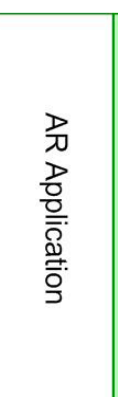 & 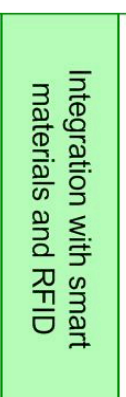 & 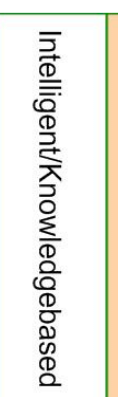 & 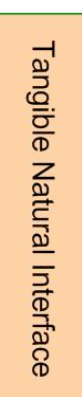 & 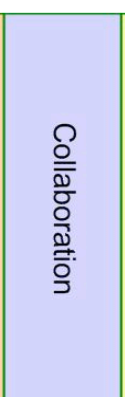 & 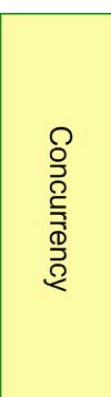 & 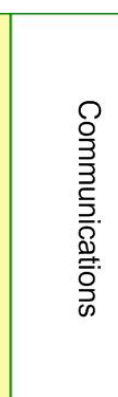 & 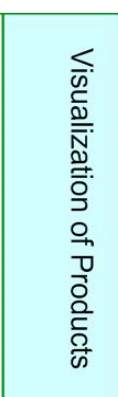 & 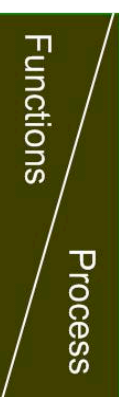 \\
\hline 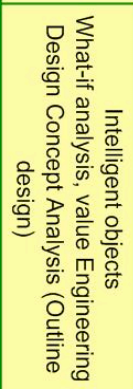 & 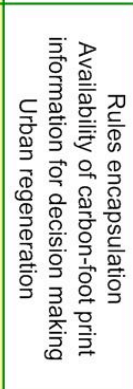 & 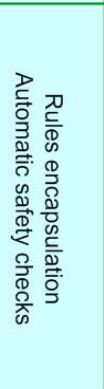 & 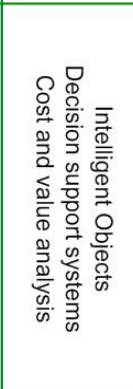 & 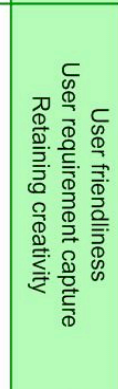 & 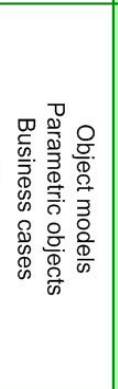 & 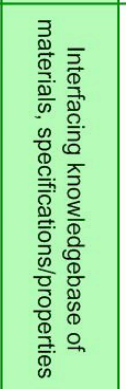 & 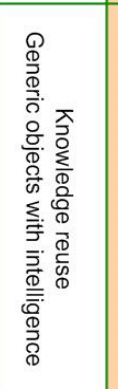 & 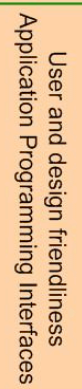 & 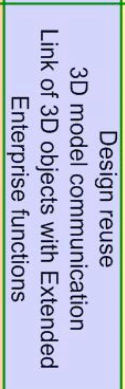 & 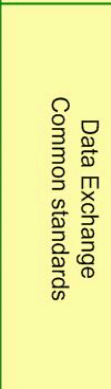 & 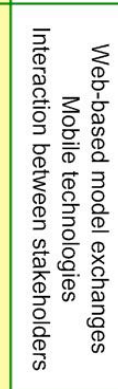 & 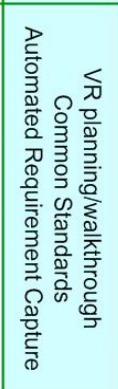 & 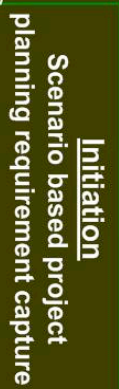 \\
\hline 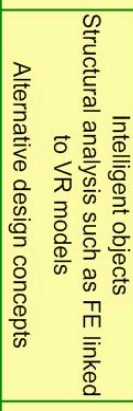 & 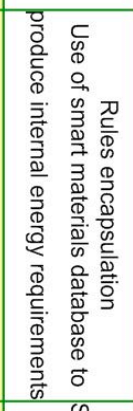 & 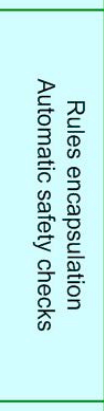 & 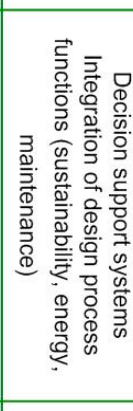 & 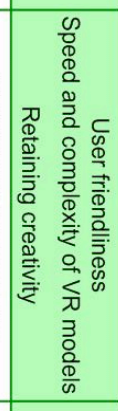 & 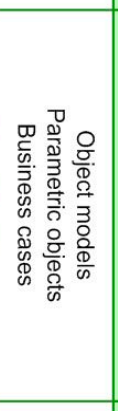 & 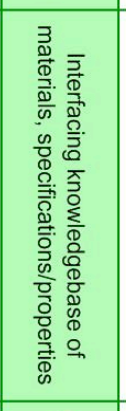 & 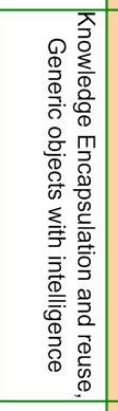 & 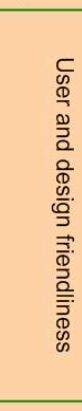 & 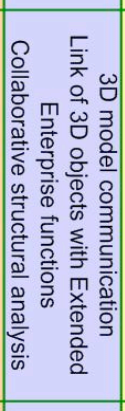 & 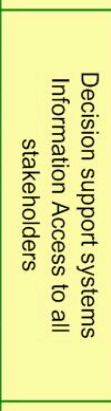 & 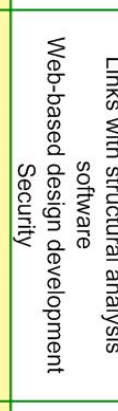 & & 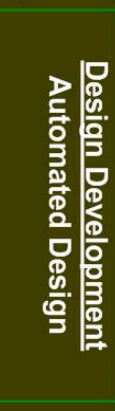 \\
\hline 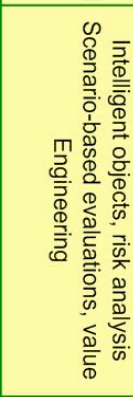 & 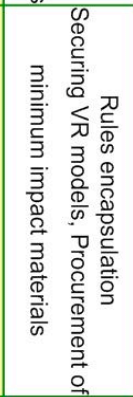 & 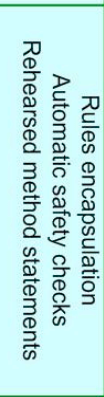 & 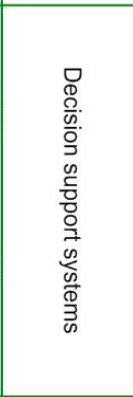 & 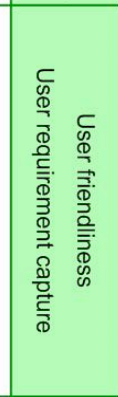 & 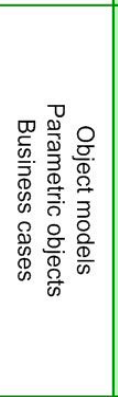 & 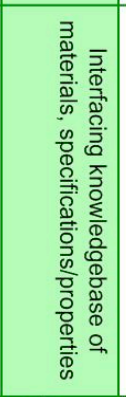 & 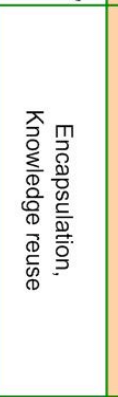 & 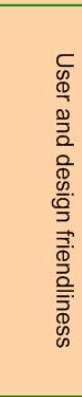 & 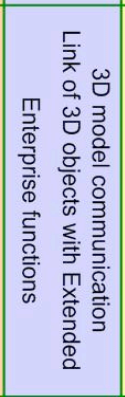 & 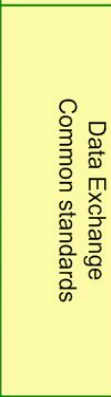 & 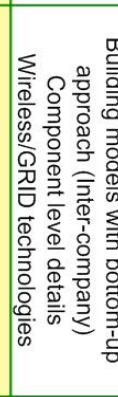 & 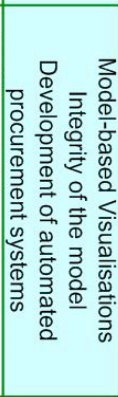 & 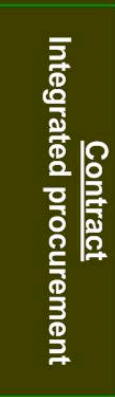 \\
\hline 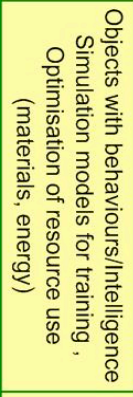 & 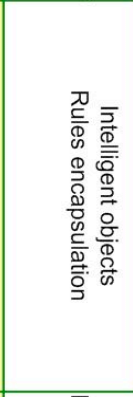 & 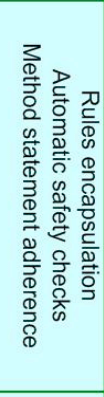 & 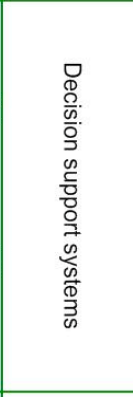 & 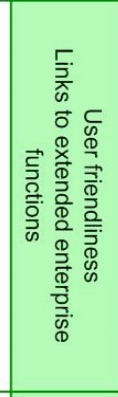 & 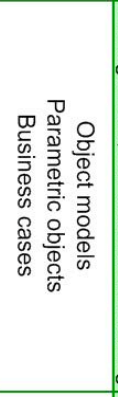 & 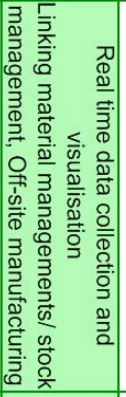 & 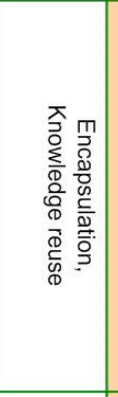 & 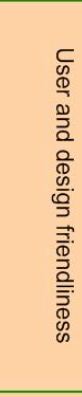 & 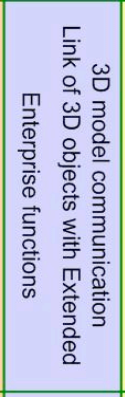 & 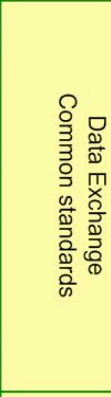 & 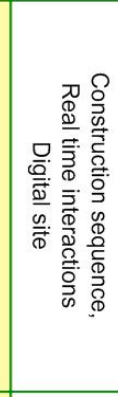 & 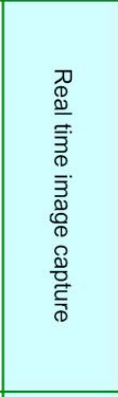 & 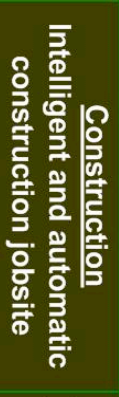 \\
\hline 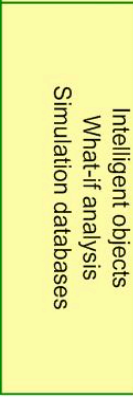 & 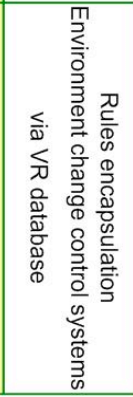 & 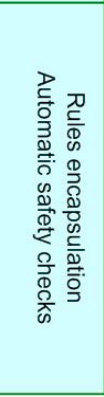 & 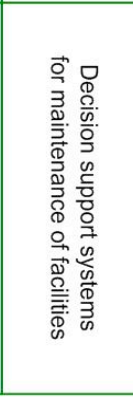 & 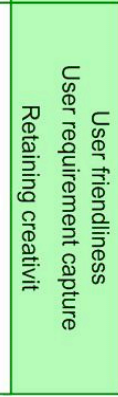 & 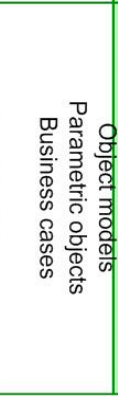 & 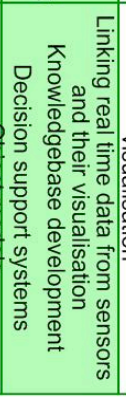 & 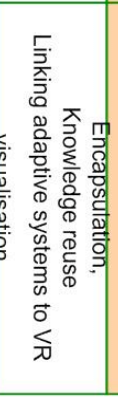 & 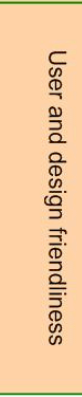 & 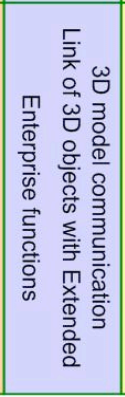 & 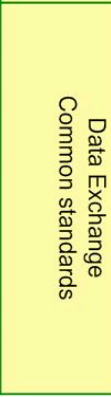 & 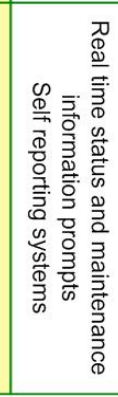 & 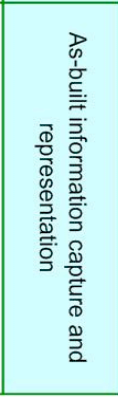 & 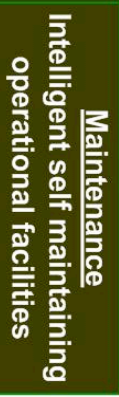 \\
\hline
\end{tabular}

FIG. 2: R\&D towards 2030 
The industry structure will advance in 2030 and many current barriers will not exist and new barriers will emerge. The experts envisaged that the built environment and its business processes towards 2030 will be different and will comprise of following characteristics and functions:

- $\quad$ Semi-Automated Construction: The design of buildings and infrastructure will be semi automated and there will be integrated supply chains using technology and communicating seamlessly all the product and process information as a normal routine. The 3D and VR models will encompass all parametric designs and the design will be facilitated through the use of intelligent object libraries. The construction process will be more or less automatic.

- Integration: The design and construction will be concurrent and decisions will be made prior to execution through integrated VR technologies i.e. early in process of the project development. There will be coherent integration of product and process models.

- $\quad$ Flexibility: The industry will be more flexible to accommodate changes in the design or processes quickly with the support of advanced IT systems. The VR systems will be flexible to accommodate for late changes and will embrace manufacturing philosophy, thereby providing better modelling.

- Automated requirement capture: Due to the technological advancement, a common design standard, and seamless integration of data, users will be able to input their requirements providing clients realistic briefing.

- $\quad$ Single stop: Products will be supplied by a single multidisciplinary company.

- Integration: Sustainable, virtual, distributed concurrent collaborative design through networking with most projects utilising e-planning with environmental considerations, aesthetic appearance and urban environment.

- $\quad$ Educated and skilled workforce: The industrial workforce will be educated and competent in using the technology. VR will be used as a training tool for engineers and construction workforce.

- Standardisation: A common standard for designing and communication of designs and associated applications will emerge. It is likely that CIS/2, IFC or similar standard will be a common place. Generic standard building blocks will be available for design and applications will support ease of modelling to concentrate on design creativity.

- Hardware interfaces: Haptic interfaces, multimodal interfaces, augmented reality, mixed reality and other advanced VR technology will find their application in the industry for interaction with VR model.

- $\quad$ Design: VR will be used to examine design performance. The development of VR models will use natural sketches and informal and parametric VR. The design will done using 3D intelligent objects. The design process will include whole life cycle costing and value engineering analysis, health and safety issues.

- Mobile Technology: Mobile technology will be advanced to a greater extent thereby supporting enhanced capacity of transferring and communication large VR models seamlessly. Wireless and GRID technologies will be the enablers for the interaction, processing and visualisation of information using holistic model.

- Intelligent infrastructures: VR will be common interface to visualise and interact with the information provided by the intelligent elements of the building/infrastructures such as sensors, transmitters and microprocessors. The intelligent elements will be embedded into the structures such as walls, furniture etc. VR will be used in the selection and design of smart materials thereby incorporating sustainability and other environmental considerations in a virtual laboratory. 
Figures 3 and 4 show a more elaborate presentation of the futuristic roadmap. Figure 3 shows built environment business process against enablers, challenges, functions and future built environment. Figure 4 gives a more elaborate summary of the whole business processes. Figure 5 shows specific R\&D initiative for outline design processes utilising VR technologies which has been developed through the brain storming sessions.

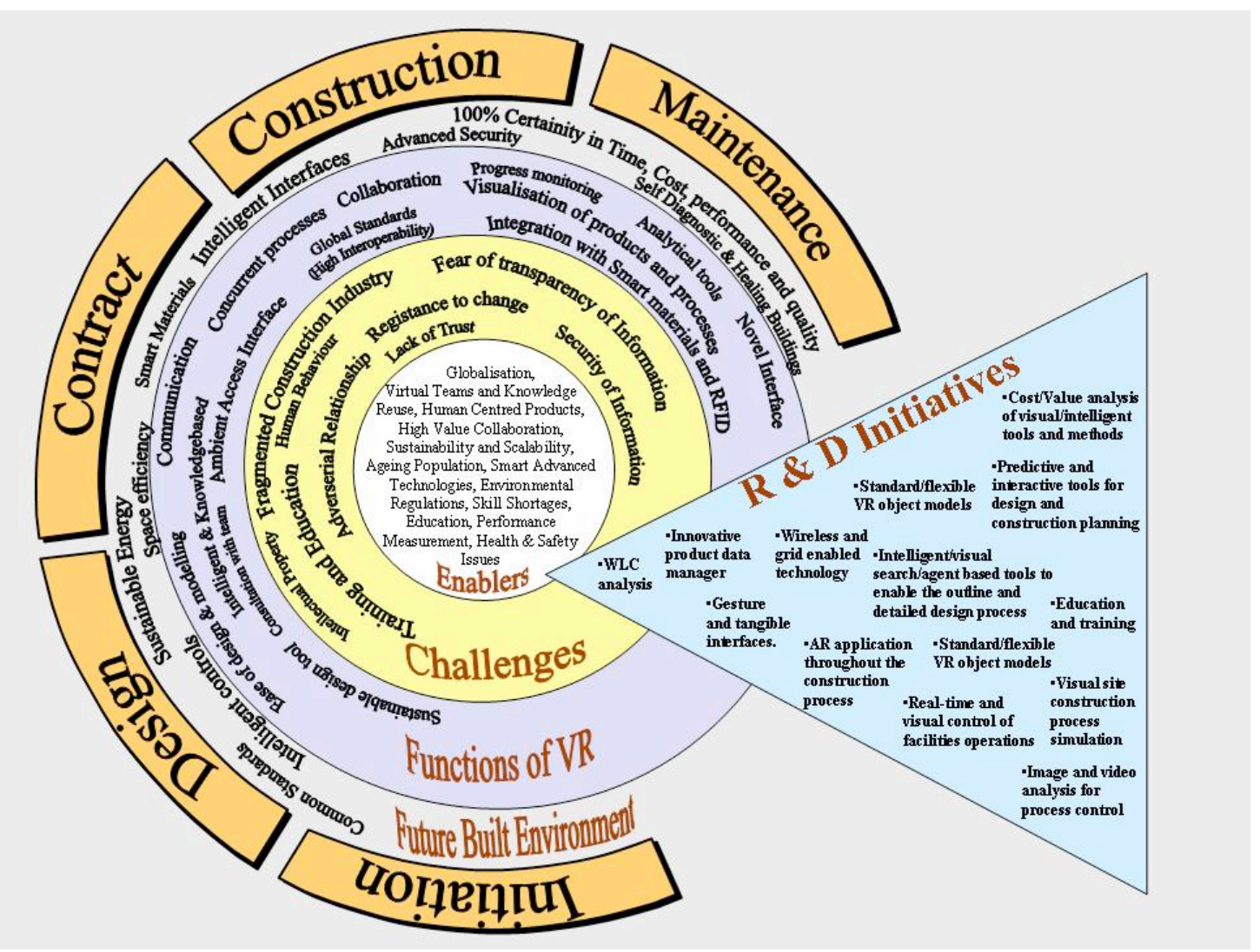

FIG. 3: Abstract of VR-Roadmap, Vision for 2030 


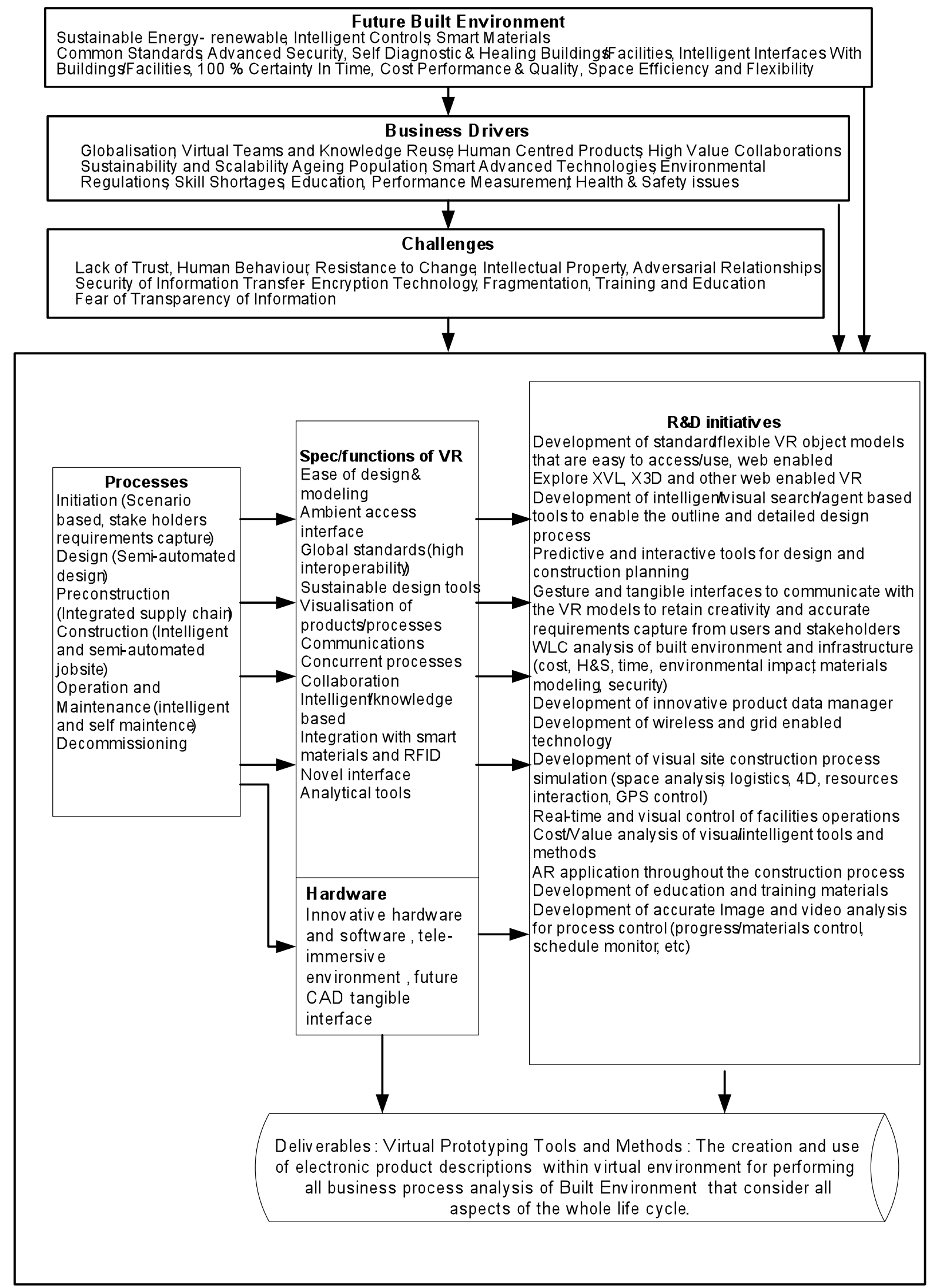

FIG. 4: VR-Roadmap, Vision for 2030 


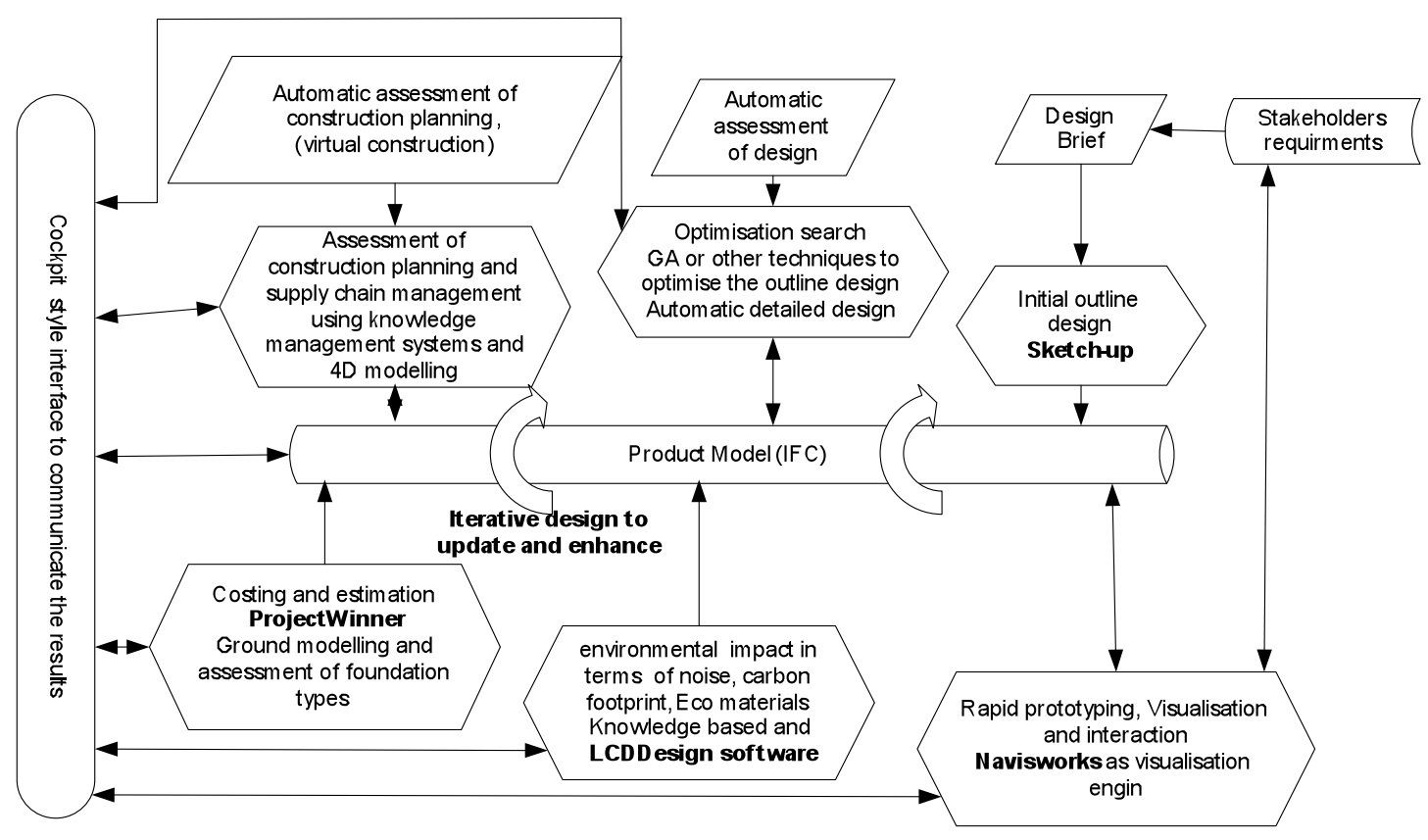

FIG. 5: Overall architect c

As can be seen the initiative is composed of a number of R\&D projects that will be focused at the outline design processes. These projects are which reflect usage scenarios to support the realisation of the vision:

- Briefing and early sketch design

This project will develop a protocol for identifying and processing stakeholders requirements, with the main emphasis being in the information that one can expect to get from the client's design brief. The latter will be used in conjunction with input from architects to develop one or more rapid outline 3D design sketches. Available Standard design rule and guideline databases for space planning and constraints will be used to inform the outline design. All design constraints will be within the Design Brief, which will be expressed in either numerical or natural language forms and where possible will be converted into forms which can be used electronically so they can be used within the other components of the proposed system.

The initial prototype, including space objects, will be stored in visual BIM databases to be accessed by the other assessment and design processes as described below. It is envisaged that the construction supply chain will be involved and engaged in briefing process. Alternative designs will be produced and examined under different constraints and business cases. Contract types like PFI and PPP will be one of the enablers for utilising VR technologies at the briefing and outline design stages. In this case, the main contractor will take full responsibilities of the design, construction and running of the facilities. Supply chain will not only supply and construct but will be involved in maintaining the part of the facilities that they are responsible for.

- Site and geotechnical constraints.

This project will use International Standards to draw from sources of geo-spatial information to create an integrated site representation for use during the early stage design process. Sources should include mapping from Ordnance Survey, British Geological Survey, historical mineral extraction reports, Land Registry, DEFRA and Local Authorities including adjacent buildings and services, as well as commissioned site investigation survey results of the topography and ground geology, hydro-geology and details from bore-holes. By assembly all this information in a common repository, the concept and structural design can be influenced. Visual representation and augmented reality will be used to assist the construction team in understanding the site constraints and services that pass through the site and therefore minimise the risk associate with such constraints.

- Initial structural frame design

The objective of this project will be to search through the many options (at least $5 \times 106$ ) for the structural frame. The choice of frame and structural system for the flooring will be influenced by information from the BIM 
model, the geotechnical and site data plus the structural frame design software's own inbuilt information. The architect will be asked to define any column free areas etc. The software will elicit from the designer(s) their objectives and then search for a series of frame solutions that meet these. These solutions will have been analysed using a suitable method such as finite element analysis to ensure that they are structurally viable. The futuristic VR technologies that needs to developed to support this case scenario will the coupling of visual representation of a building opponent and a intelligent structural analysis of such a component. When a number of components joint together, for example beams, columns and slabs, an automatic structural analysis will produce structural sizes of the components under different measures which can include minimise cost, decrease complexity, improve special design, etc.

\section{- Construction planning, costing and duration evaluations}

This will develop the initial construction work packages and their dependencies for the proposed project. Workbreak-down structure and construction activities ontologies developed by other research projects will be used to develop and formulate initial work packages. Knowledge based systems will be developed to advise on possible method statements, major equipment needs, foundation types and duration for each work package.

4D planning and modelling developed by Dawood et al 2006 (a) and Dawood et al 2006 (b) will be adapted and used to rehearse construction processes to evaluate project duration and identify the interface between different trades/or and work packages. This case scenario will be vital for rehearsing of construction processes to identify work flow, site congestions and layout, execution space conflict and others. Other functions will include forecasting of project cash flow and cost against virtual site progress.

\section{- $\quad$ Sustainability and environmental assessment}

The objective of this project is to gather all relevant information available from researchers working in the field of carbon footprint, life cycle environmental areas and de-construction and develop scenario analysis tools to assist in the environmental impact assessment. This includes the development of a comprehensive database of the carbon footprint of wide range of building materials in common use or likely to be developed for construction application. This project will also provide a practical conceptual route that simplifies the analysis of the 'trade-offs' between construction materials and components-from an environmental, energy use and deconstruction aspects. It is envisaged that visual models of buildings will be integrated with Environmental impact analysis (EIA) where all the analysis can be interactive and visual. It should mentioned that the EIA will include Whole Life Cycle Analysis (WLCA), Whole Life Cost Analysis (WLCA), Energy Profiling (EP) and Carbon Footprint Prediction (CFP). Methods and approaches for simulation and visualisation tools for energy profiling and trade off's between different constraints will be developed and validated to enable energy efficient life-cycle use of buildings including the utilisation of local energy networks. A new approach of integrating simulation with real time data capturing sensors will be researched, developed and validated. The technology will be deployed on new and current building stock.

\section{- $\quad$ Rapid Prototyping and visualisation of BIM}

This project will develop methodologies for rapid prototyping of visualisation of BIM. DirectX and openGL tools will be used to develop a high quality visual representation of the project throughout the development processes. Facilities for users to interact with the product and modify design if needed. The visualisation will provide advanced features such as gesture recognition to activate commands, head tracking to facilitate the correct perspective of stereo images as the user's view changes, hand tracking to enable direct interaction with the visualised objects and holographic quality representation. The Powerwall (a high-end VR display) is an excellent visualisation facility but no more than this. This research will investigate and provide the additional user interaction and communication functionality to turn it into an advanced design facility which will take the EC's basic 3D models (discussed earlier on) and allow the designers to evaluate, change and add details. Rapid prototyping will be integrated with visual BIM models so that any changes in BIM can be reflected in real-time in the prototype. Intelligent design will be integrated with the rapid prototype engine so that it will be able to facilitate an intelligent relationship between building objects and spaces. For example, if the construction team (designers, clients and supply chain) decided to add an extra floor or change the use of a particular floor, the system should be able to suggest structural changes or redesign part of the building to structurally accommodate the new changes.

- Client dashboard (cockpit style) and web services 
This project proposes the development of highly interactive visual tools that can interact with all assessment processes and abstract information in a way that can be informative and effective to communicate results and tradeoffs. This project will also develop a web enabled BIM and all related web collaboration and services. An integrated databases to incorporate BIM and the management layers for access rights and collaboration. IFCsvr 2.2, EPM and other commercial software will be used for the development of the BIM.

\section{DRIVERS FOR CHANGE}

VR will play a major role in the design, management and operation of the Built Environment embracing the "Cradle to Grave" concept. VR will be linked to other applications with a natural interface. Following the advancement in the mobile technology, all the buildings constructed will be intelligent and will utilise VR technology. Eventually, the Construction Industry will follow the route of manufacturing and aerospace industries where VR modelling and simulation technology is used extensively. The drivers for change in Technology and Research towards 2030 will be:

- Customer understanding: Client lead is required to force change. Using visualisation, clients have better idea of project and the clients will demand higher uptake and use of VR in projects as they are people paying for facility. Clients and major firms will demand for the advanced VR technologies to evaluate design, construction and operational performances.

- $\quad$ Public Participation-Public participation will be increased in the development of projects and VR will provide a tool for planning permission, provide consultation, end user involvement and their links.

- $\quad$ End user involvement- End users can be involved in urban and building development in planning process.

- Government regulations: Government regulations are getting tighter and include the aspects of safety, environmental considerations, energy reuse and sustainability issues. The legislation on the use of technology would be a strong driver for change

- Sustainability: Sustainability requirements such as minimisation of negative impact on the natural environment minimise waste and use of renewal resources will force the industry to do several analyses before documentation, design and use of the facilities and VR will be a common technology used in the construction industry. Procurement system will use sustainability as main criteria as opposed to the current low cost bid criteria.

- $\quad$ Simulation Capability: VR will be linked to other IT systems for the environmental and life cycle analysis to inform decision makers in the design and construction of the built environment to simulate, assess and analyse different scenario with the use of different material components and different construction methodology.

- Incentive- The development of low cost technology with its interoperability will increase the use of VR commonly.

- Competition: Due to growing competition between the construction company to provide efficient and quality products/services between construction companies, VR will be used by the companies to be upfront and minimise saving by "testing before construction".

- $\quad$ Requirements for knowledge economy: There is a need to develop trust among participants in the $\mathrm{BE}$ so that knowledge is shared using advance IT for mutual benefit.

- Internet and mobile technologies: Internet and mobile technologies are developing in a faster pace and their enhanced capability will provide ease of using VR models of any complexity. Therefore, e-submission of tenders and use of VR in planning will be a routine work. Mobile devices such as hand held computers, PDAs and other equipment will be utilised on the construction sites for data collection, project monitoring and quality control thereby minimising waste on construction sites.

- $\quad$ Partnering, Collaboration - The partnering and collaboration between companies requires sharing resources between partners of a project and VR will be utilised better to exchange information. Development of international alliances between researchers and users of VR working in collaboration will lead to mutual benefits. As skills of the construction workforce will be developed and thereby the interactions between the stakeholders will be effective. 
The issues of barriers have been discussed and identified and it was concluded that major barriers could be: lack of finance to support big industrial initiatives, lack of trust, lack of industry uptake of the technology, lack of highly qualified civil and building engineering personnel with the knowledge of VR and lack of research work in the area of cost/value analysis of the VR technologies. Also, challenges were discussed and a summary is given below and more elaboration is given in figures 3 and 4 :

- Maintaining Artist's impression/ reality

- Trade institutions (like ICE, CIOB and others) support through legislations and support the use of the technology

- A better design communication tool

- $\quad$ Process control - who can change it?

- Legal considerations and subjectivity inclusion in the technology

- Ability of architects to embrace the technology

- Quick and dirty to show potential

- Natural interfaces

\section{DELIVERING THE VISION}

The realisation of the vision 2030 requires several steps that the industry and research and development activities have to adopt. The key elements for the achievement are:

- $\quad$ Networking: Network of academics, industrial practitioners and technology frontiers should work together identify real needs of the industry and developing customised application, best practice examples of using VR.

- Education: Construction industry practitioners should be provided with education and training opportunities about the technology. VR should be an inherent part of the Built Environment Courses and technology transfer programs should be developed and delivered to the industry. Best practice guides should be developed and shared across the industry.

- $\quad$ Product and process model integration: Using VR in modelling processes and products and their integration to make informed decisions from initiation to decommissioning of the project. The integration of products and process models is a key for increased use of VR.

- Standardisation: Initiatives to develop standards need to be prioritised so that a common standard will be adopted to model products and process information is included with the object model. Initiatives such as IFC development is an example.

\section{CONCLUSIONS}

The objective of the paper was to report on the development a 'VR Roadmap: A vision for 2030' for the built environment. The methodology and process for delivering the VR roadmap was discussed and articulated. The future thrust for R\&D will be to make the technology simple to use and accessible/integrated to key new generation tools to aid collaborative design, concurrent engineering and provide digital architecture in the form of a single internet based interface that retrieves related and shared data in the form of images and drawings etc and visualises the whole-life cycle of projects. The key challenge in VR development is to retain individuality and artistic design/creativity and have capability and flexibility to capture and model user/client requirements. Finally, industry, academia and technology developers will work more closely together in the future to develop simple to use VR tools to cater for the requirements of the construction industry.

\section{REFERENCES}

Boyd, L. 1998, Digital Factories Computer Graphics World, May 1998, pp. 45-52.

Dawood, N. and Mallasi, Z. 2006a. Workspace Competition: Assignment, and Quantification utilizing 4D Visualization, Paper accepted for publication in the Computer-aided civil and infrastructure engineering, 21, pp 498-513, 2006. 
Dawood, N. and Sriprasert, E. 2006. Construction Scheduling using Multi-Constraints and Genetic Algorithms Approach, Construction Management and Economics, 24, pp 19-30, Jan, 2006

Dawood, N., Scott, D., Sriprasert, E. and Mallasi, Z. 2005. The virtual construction site (VIRCON) tools: An industrial evaluation, ITcon Vol. 10, Special Issue From 3D to nD modelling, pg. 43-54, http://www.itcon.org/2005/5

Khatab, A., Dawood, N., Hobbs, B. Development of an Integrated Virtual Reality Decision Support System (IVR-DSS) for Outline design for R.C.B.S, CONVR 2005, Durham, UK.

Lee, A., Wu, S., Marshall-Ponting, Aouad, G., Cooper, R., Tah, J., Abbott, C. and Barrett, P. S. nD modelling RoadMap, A vision for nD-Enabled Construction, Salford University report, 1994.

Miles, J., Cen, M., Taylor, M., Bouchlaghem N., Anumba, C. and Shang, H. 2004. Linking sketching and constraint checking in early conceptual design, Beucke K. et al (eds) $10^{\text {th }}$ Int. Conf. on Comp in Civil \& Building Eng, 11pp.

Quayle, S. D., Taylor, S. M., Rennie, A.E.W and Rawcliffe, N. 2005. From concept to manufacturing: effective use of CAD and FEA without compromising design intent, $6^{\text {th }}$ National Conference on Rapid Prototyping and Manufacturing, 2005.

Rischmoller, L., Fischer, M., Fox, R. and Alarcon, L. 2001. 4D planning and scheduling (4D-ps): grounding construction it research in industry practice, Coetzee G, Boshoff F (ed.); IT in construction in Africa 2001; Mpumalunga, 30 May - 1 June, South Africa, 2001.

Sacks, R., Eastman, C. and Lee, G. 2004. Parametric 3D modelling in building construction with examples from precast concrete, Automation in Construction, 13, 91-312.

Shaw, D., Miles, J. and Gray, W. 2005. Conceptual Design of Orthogonal Commercial Buildings, Proc of $8^{\text {th }}$ Int. Conf on the Applic of AI to Civil, Struc. \& Env. Eng, Topping B (ed), Civil-Comp Press, UK, paper 1.

Tim Watts, 1998. G.A. Peter Swann and N Pandit, Virtual Reality and Innovation Potentials, Business Strategy Review, 1998, Vol. 9, Issue 3, pp 45-54.

Tizani, W., Smith, R. and Ruikar, D. 2005. Virtual Prototyping for Engineering Design, CONVR 2005, Durham, 12-13.

UK Business Potential for Virtual Reality, Executive Summary, Information Society Initiative, DTI, Feb, 2000.

Wilson et al., 1996. Virtual reality for industrial applications: Opportunities and limitations. Nottingham, Nottingham University Press. 